\title{
Reflection on the Variation Training Behavior of Teaching and Training Institutions in the "Double Reduction" Policy from the Theory of Human Nature Hypothesis
}

\author{
Hailong Li, Yongxing Lin \\ Faculty of Education, Guangxi Normal University
}

\begin{abstract}
Under the "double reduction" policy, some discipline training institutions have mutated training behavior, which seriously hinders the implementation of the policy. The basic mission of public policy is to protect civil rights and freedoms, and its process should follow certain human nature presuppositions. Through the theory of human nature hypothesis, this paper analyzes the internal incentives of the variation training behavior of teaching and training institutions in the implementation of the "double reduction" policy. And finds that it is not only related to the instinctive response of rational economic people, but also dominated by the expected fair behavior of social people. Therefore, we should face up to the legitimate needs of education and training institutions, strengthen the flexibility of policy implementation, and change the utilitarian thought of education.
\end{abstract}

Keywords: "Double reduction" policy, Human nature hypothesis, Variation training.

\section{Introduction}

In July 2021, the general office of the CPC Central Committee and the general office of the State Council issued the opinions on further reducing the homework burden and after-school training burden of students in the stage of compulsory education (hereinafter referred to as the opinions), which called for rectification and management of academic burden and after-school training. All localities immediately took relevant actions around the requirements of the opinions. However, in the early stage of policy implementation, the invisible variation of education and training institutions appeared everywhere, which seriously hindered the effective implementation of the "double reduction" policy. In this context, based on the human nature hypothesis theory, combined with the "double reduction" series of policy texts issued by the state and local governments, this paper explores the human nature factors behind the variation behavior of teaching and training institutions, and puts forward relevant suggestions to ensure the smooth implementation of policies.

\section{Human Nature Presupposition in Public Policy}

The practical activities and relationship networks between human beings constitute the social unit, and the information exchange and energy transmission between groups constitute the social system. Therefore, the assumption of human nature has become the fundamental starting point of social science practice and theoretical research. The essence of public policy is to explore the law of human behavior in policy practice. In short, the theory of human nature hypothesis is also the foothold and destination of public policy.

In the period of agricultural civilization more than 2000 years ago, the ancient Greek scholar Aristotle proposed that "man is a political animal", which revealed the era of "political man" in the history of human management.
As early as the 18th century, Adam Smith put forward the theory of labor exchange economy, from which the hypothesis of "economic man" originated. The theory holds that people generally pursue interest reward, are good at seeking advantages and avoiding disadvantages in order to maximize their own interests, and are unwilling to bear any responsibility and risk. The activity practice of public policy is based on the interest game between individuals or groups, and its essence is the interest demands of different roles. Interest has become the primary driving force of individual or group policy participation, and the pursuit of interest is in line with people's general nature. Therefore, it can be set as "economic man".

From the 1930s to 1940s, Mayo proved through Hawthorne's experiment that workers' work efficiency was not simply driven by economic interests, and then put forward the hypothesis of "social man". He believes that workers are not only related to personal economic interests, but also have needs for friendship, respect and social networking. Marx and Engels once conceived of solving the problem of human nature with needs. However, the inner extension of human nature is the primitive instinct of animals, and the outer extension is the physiological and spiritual needs under the symbols of social roles. The infinity and complexity of human nature determine the diversity of needs. It is obviously difficult to solve the problem of human nature without distinguishing needs. Maslow, a contemporary humanistic psychologist, proposed to divide human needs into physiological needs, security needs, social needs, respect needs and self-realization needs. ${ }^{[1]}$ He believes that people's needs are diverse and divided into primary and secondary. As Marx said, "the reason why man is different from all other animals is that man's needs are infinite and extensive." The tortuous process of public policy formulation and implementation also stems from the complexity and infinity of human nature, and then externalized into the infinite diversity of human needs. Only through continuous correction 
and adjustment can we meet the needs of the masses and ensure the effective implementation of policies. On this basis, individuals or groups of public policies can be set as "social people" and "self-fulfilling people".

In the 1980s, in his book " $Z$ theory - how the United States meets the challenge of Japan", the Japanese scholar William Dani proposed to analyze the similarities, differences and limitations of American and Japanese enterprises from a cultural perspective, and advocated that the common enterprise goals and values are the premise of success. This theory infiltrates the management thought into the cultural level, and tries to seek effective means to realize efficient management from groups with different national beliefs and cultural backgrounds. Although the concept of "cultural man" is not clearly put forward in this work, the current academic circles have agreed with its emphasis on "culture has the function of determining human behavior". Culture is the net of meaning. Each interest subject in public policy is the representation of culture, carries certain meaning and value, and uses symbols, symbols and concepts to seek meaning. In short, each organization, including individuals, consciously or unconsciously seeks meaning from their own life experience, and produces a certain state of affairs or order in their own policy related behavior and in the game with the social interests of others. Therefore, to some extent, the subjects in public policy contain the hypothesis of "cultural man".

To sum up, the basic mission of public policy is to protect civil rights and freedoms and safeguard human dignity. Therefore, its process should follow a series of presuppositions of human nature. The theoretical foundation of this study is to explore the deviation in public policy through the theory of human nature hypothesis.

\section{The Time Value of "Double Reduction" Policy and its Human Foundation}

The "double reduction" policy takes "correcting the educational concept, adhering to the educational attribute and following the educational law" as the value connotation, and takes the human nature hypothesis theory as the implementation logic basis ${ }^{[2]}$. In the process of policy implementation, exploring its value implication and implementation logic is helpful to analyze the factors behind the deviation of policy implementation.

\subsection{The Special Mission of the "Double Reduction" Policy}

Educational policy refers to the action basis and criteria stipulated by political parties, governments and other political entities to coordinate the internal and external relations of education in order to achieve certain educational objectives and tasks. ${ }^{[3]}$ First of all, the "double reduction" policy is universal and a political measure reflecting the class will of the broad masses of the people. Economic status determines different political demands and interest demands, while the political and interest demands of the same class are basically the same. Guided by the thought on socialism with Chinese characteristics for a new era, the "double reduction" policy is the most powerful evidence that it represents the interests of the people of all ethnic groups in the country. Secondly, the "double reduction" policy is an effective guarantee for the educational rights and interests of different social groups. Taking students as the foundation and returning to the mission of educating people is the main principle of the "double reduction" policy, which is also the most powerful explanation to protect students' educational rights. In addition, the reduction of students' homework, the reduction of parents' burden, the play of the main role of the school and the standardization of school training institutions all give full consideration to the rights and interests of different classes of people from different angles.

\subsection{The Intrinsic Value of the "Double Reduction" Policy}

The "double reduction" policy has the universal representation of the concept of burden reduction, but its connotation is different from the previous burden reduction policies. First of all, from a systematic perspective, the introduction of the "double reduction" policy is to correct the deviation of the educational concept. The current educational situation of "utilitarian and short-sighted" has seriously hindered the development of China's basic education. Its root is the immersion of the concepts of "utilitarian education" and "advanced education". The "double reduction" policy adheres to the fundamental task of Building Morality and cultivating people, focuses on building a high-quality education system, reducing students' burden, reducing family education expenditure, repairing the education ecology of the all-round development of students' morality, intelligence, body, art and labor, and helping education get out of the "theater effect" of involution. Secondly, from the perspective of attribute, the "double reduction" policy prohibits capital binding basic education, which is a adherence to the principle of public welfare of education. The original teaching and training institutions are both educational and commercial enterprises, but driven by huge economic interests, discipline teaching and training institutions have become capital profit seeking industries. The "double reduction" policy resolutely rectifies and controls the training behavior of discipline after-school training institutions, and solves the problem of excessive and excessive training. Severely investigate and deal with institutions with serious problems such as unqualified, disordered management, false publicity and foreign capital infiltration according to law and regulations. In principle, it maintains the public welfare of education and promotes educational equity. Finally, based on the interpretation of social development, the implementation of the "double reduction" policy is a new understanding of the law of education. The power of social sustainable development comes from human development, and human sustainable development is based on the correct understanding of the law of education. The "prisoner's dilemma" in education urges parents to sign up for classes blindly, so as to increase the sense of security in the pursuit of education and reduce educational anxiety. This not only violates the law of education, but also endangers the development of students' physical and mental health. The implementation of the "double reduction" policy is to fundamentally get rid of the intrusion of external anxiety factors, optimize the growth environment of students, promote the all-round development of students, increase the fun of on-campus courses and promote the skills of off-campus training on the premise of reducing a large number of repetitive and monotonous 
knowledge burden, so as to meet the diversified needs of students.

\subsection{Human Nature Hypothesis is an Important Basis for the "Double Reduction" Policy}

The "double reduction" policy is artificial. In short, the formulation, implementation and debugging of the "double reduction" policy are inseparable from people's participation. Therefore, the theory of human nature runs through the "double reduction" policy from beginning to end. This paper systematically discusses the human nature basis of the "double reduction" policy from two dimensions: horizontal and vertical. First of all, from the horizontal dimension, the "double reduction" policy is formulated by the national government and implemented by various regional departments. It is intended to solve the current situation of heavy academic burden of students and chaotic management of out of school teaching and training institutions in the field of education, so as to realize the all-round development of students and social harmony and stability. Its essence is the redistribution of original interests and the derivation of new rights. It can be seen that the formulation subject, implementation object, policy content and policy essence of the "double reduction" policy are related to the production relationship between people, as well as the human nature relationship and interpersonal relationship in the bureaucracy. Therefore, the "double reduction" policy is constrained by human nature, and its policy concept is also artificial. Secondly, from the perspective of vertical procedure implementation, the problem to be solved by the "double reduction" policy stems from the excessive expansion of human self-interest. The policy formulation is completed by the government, but the policy implementation needs the cooperation of education administrative departments, schools, families and after-school training institutions. Moreover, the policy evaluation is completed by the joint efforts of policymakers, executors and researchers. The policy modification and debugging finally return to the government level. Therefore, the procedural basis of the "double reduction" policy is human behavior, and the implementation of the "double reduction" policy is artificial. To sum up, both the horizontal conceptual elements of the "double reduction" policy and the degree of program implementation are closely related to human factors, that is, determined by human nature.

\section{The "Human Nature" Inducement Behind the Invisible Variation of Educational and Training Institutions}

Through the theory of human nature hypothesis, this paper analyzes the internal incentives of the variation training behavior of teaching and training institutions in the implementation of the "double reduction" policy, and finds that it is not only related to the instinctive response of rational economic people, but also dominated by the expected fair behavior of social people.

\subsection{The Instinctive Reaction of Rational Economic Man}

The rational economic humanity hypothesis holds that people's every move is to seek the maximization of their own interests. Based on the assumption of rational economic human nature, the inducement of invisible variation of education and training institutions is mainly due to the instinctive response of their role of rational economic man. After the implementation of the "double reduction" policy, a large number of online and offline discipline training institutions were strictly managed, and a large number of training institution teachers were laid off. Under the economic stimulus and policy constraints, discipline training institutions that have been strictly investigated and regulated have found another way to survive, looking for loopholes in policy supervision, and trying to make a new appearance for other training forms. Under the economic stimulus and policy constraints, discipline training institutions that have been strictly investigated and regulated have found another way to survive, looking for loopholes in policy supervision, and trying to make a new appearance for other training forms. Due to the strong concealment of underground and family private education, it is difficult for the regulatory authorities to obtain evidence, investigate and supervise it. Therefore, many discipline training institutions, under the names of "study tours and summer camps", and under the cloak of "home teachers" and "crowdfunding private education", carry out discipline training in violation of regulations and disguised forms. On September 6, 2021, the general office of the Ministry of Education issued the Notice on Resolutely Investigating and Dealing with the Issue of Discipline out of School Training in Disguised Violation. The notice stressed that institutions or individuals who violate the relevant provisions of the training subject and have incomplete licenses, carry out discipline training in the name of consultation, cultural communication, "housekeeping services", "home teachers" and "crowdfunding private education", and will be strictly investigated in accordance with the law. However, according to self-media reports, recruitment information such as high salary employment of "home teachers" and "full-time nannies" can still be seen in the talent market.

\subsection{Expected Fair Behavior of Social People}

The expected fairness theory of American psychologist Adams believes that everyone will make a social comparison between their own labor and income and the labor and income of others, and will also make a historical comparison between their current labor and income and their past labor and income. ${ }^{[4]}$ If he finds that his income and expenditure ratio is equal to that of others, or the current income and expenditure ratio is equal to that of the past, he will think it fair and reasonable, so that he will be happy and work hard, and vice versa. Based on the assumption of social humanity, the invisible variation of education and training institutions is their homeopathic behavior under the theoretical thinking of expected fairness. First of all, the managers or teachers of discipline training institutions compare the real income with the past history, and their income has plummeted compared with the past, even difficult to survive. Secondly, the "double reduction" policy has little impact on non-disciplinary training institutions, and their income is very different. Under the double comparison between the past and the present, and between itself and other training institutions, the managers or teachers of discipline training institutions feel unfair, and then seek new measures such as invisible variation to make up for their relative income. 
At the same time, under the "double reduction" policy, the withdrawal of teaching and training institutions has derived disputes such as tuition compensation, student placement and labor disputes of teaching and training teachers, which makes discipline training institutions face the economic risk of bankruptcy.

\section{Reflection on the Invisible Variation of Teaching and Training Institutions}

The process of policy implementation is not only a mechanical and administrative organization or management process, but also "a political process, a process in which multiple subjects participate in the game and take collective action". ${ }^{[5]}$ Under the "double reduction" policy, the invisible variation of education and training institutions involves multiple participants, including the education and training institutions themselves, relevant policy implementation departments, families and other subjects. In order to implement the "double reduction" policy effectively and effectively and further standardize the market of teaching and training institutions, we should start from the following aspects. First of all, the education department should pay attention to the needs of teaching and training institutions, guide the rational transformation of teaching and training institutions, and explore and improve the exit mechanism and relevant guarantee mechanism of teaching and training institutions. Secondly, strengthen the flexibility of policy implementation. After the implementation of the "double reduction" policy. For example, Yulin Education Bureau of Shaanxi province implemented the policy very quickly, and explicitly prohibited all discipline after-school training institutions in the stage of compulsory education. ${ }^{[6]}$ However, there are many non-profit training institutions in discipline training institutions. The comprehensive shutdown of "one size fits all" will not only strike their school running enthusiasm, but even make it difficult for them to survive. "Double reduction" has typical regional differences, and it should not be "one size fits all" in administration. ${ }^{[7]}$ Therefore, while implementing policies, local education authorities should strengthen the flexibility of policy implementation, and flexibly improve and perfect the transformation and exit mechanism of education and training institutions. Moreover, parents should change the "utilitarian" concept of family education. Schools and society should guide parents to change the past "utilitarian education concept" into following the educational law of children's physical and mental development, advocate the concept of scientific parenting, and reduce parents' and children's educational anxiety.

\section{References}

[1] $\mathrm{Hu}$ Jiaxiang. A Multidimensional Interpretation of Maslow's Hierarchy of Needs [J]. Philosophical Research, 2015(08): 104-108.

[2] Ma Kaijian, Wang Guangming, Fang Fang, Zhang Ran, Ai Qiaozhen, Li Tingzhou. Educational Concept and Educational Ecological Reform under the "Double Reduction" Policy (Written Discussion) [J]. Journal of Tianjin Normal University (Social Science Edition), 2021(06): 1-14.
[3] Sun Miantao, et al. Educational Policy Theory: A Research on Socialist Educational Policy with Chinese Characteristics [M]. Wuhan: Central China Normal University Press, 2002: 11.

[4] Ye Qin. Research on employee compensation satisfaction based on equity theory [D]. Dalian University of Technology, 2008.

[5] Pan Lingyun, Wang Jian, Fan Lianxiang. Logical identification and promotion strategy of school sports policy implementation in my country: An analytical framework based on "ideas, interests and systems" [J]. Sports Science, 2017 (3): 3-12.

[6] Shaanxi Legal Network. Today, here is an announcement! Completely shut down off-campus training in primary and secondary schools [EB/OL]. (2021-7-14)

[2021-7-14] https://baijiahao.baidu.com/s?id=170525893556896498 $6 \& w f r=$ spider $\&$ for $=p c$

[7] Zhu Yiming. "Double Reduction": Cognitive Renewal, Institutional Innovation and Reform Action [J]. Nanjing Social Sciences, 2021(11): 141-148. 